the southern states. It does not even occur among the fine lot of ants kindly collected for me in the high mountains of New Mexico by Prof. and Mrs. T. D. A. Cockerell.

The subspecies diecki also occurs at Rockford under the dead leaves in the very same localities as the typical brevicorne. Often the nests of the two forms are located only a few feet from each other. The winged sexes of diecki are recorded

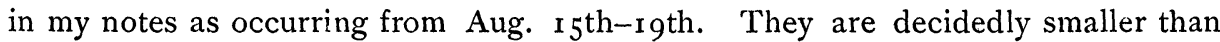
the corresponding sexes of the typical form, and the male is paler, with colorless wings and paler legs and antennae. I could detect no differences in habits between diecki and the typical brevicorne.

Austin, Texas,

April $25^{\text {th }}$, 1903.

\title{
LIFE HISTORIES OF NORTH AMERICAN GEOMETRIDAE.-XLII.
}

BY HARRISON G. DYAR, WASHINGTON, D. C.

Coniodes plumigeraria Hulst. A general account of the life history has been given by Coquillett, but.without detailed descriptions. The species has been repeatedly bred at the Department of Agriculture. Eggs were received from $\mathrm{Mr}$. E. M. Ehrhorn which were collected three miles above Saratoga, Santa Clara County, California, on an apple tree, and from these the life history was made out.

EGGs. Laid in a large mass on a twig on the flat sides. Elliptical, strongly flattened above and below, ends nearly alike, one only a little depressed. Surface minutely shagreened, somewhat transversely so, the reticulations nearly lost, elongate transversely, moderately uniform. Size $.8 \times .6 \times .4 \mathrm{~mm}$. Color dark bronzy brown.

Stage I. Head rounded, bilobed, clypeus rather high; dull black, epistoma whitish; width about $.3 \mathrm{~mm}$. Body robust, rather short, normal, not tapered, segments somewhat angularly widened centrally. Black, a narrow yellowish white line on the sharp substigmatal fold, broken in the incisures; traces of geminate yellowish dorsal line in the incisures of central segments. Tubercles rather large, rounded, brown; setae distinct but not long, brownish; feet black.

Stage II. Head erect, rounded bilobed, thin anterio-posteriorly at vertex, brown-black, reticulate with darker, scarcely shining; width $.5 \mathrm{~mm}$. Body moderate, rather thick, segments annulate, tubercles large and produced but smooth, concolorous, rounded, not tapered, black. Body slaty black, dull; traces of a geminate white dorsal band in the incisures and a broad, diffusely white lined lateral area, ill defined. Feet all black; setae fine, dark, inconspicuous. 
STAGE III. Head rounded, flat before, broadly shallowly bilobed; grayish, speckled with black, thickly so over the apex and in a patch on each side of clypeus above; a black patch at base of antennae; width $.9 \mathrm{~mm}$. Body cylindrical, moderate, normal, tubercle ii of joints 5 to 7 and 12 forming high cones, the rest elevated roundedly. Feet of joints 2 and 3 held appressed, those of joint 4 erected. Shining bronzy black with scarcely any marks. Traces of a whitish addorsal line and irregular pale areas stigmatally anteriorly, largest on joints 5 and 6 and traces of white dotted supra- and substigmatal lines. Feet all black; setae moderate, pointed, dark.

Stage IV. Head squarely rounded, lobes separated by a wide low notch, flattened before, depressed at apex of clypeus; clypeus reaching two thirds to vertex, the paraclypeal pieces nearly reaching vertex; light gray with many irregular crinkled black spots irregularly vertically arranged on the sides and partly confluent behind the vertices of the lobes; sutures of mouth black marked; width $1.6 \mathrm{~mm}$. Body cylindrical, normal, robust, not elongated; tubercles prominent, especially ii on the raised part of the abdomen and forming a stout cone on joint I2. Blackish, especially across the centers of the segments, a rather broad whitish addorsal line, broken and obscured centrally, rather distinct on the thorax and before tubercle ii on joint I2. Sides yellowish blotched, scarcely defining subdorsal, suprastigmatal, and two subventral lines which are irregularly traceable; a conspicuous black patch behind the spiracle on joints 6 and 7 , slightly indicated on other segments. Venter blackish, pale medioventrally and between joints IO-I3. Thoracic feet black, abdominal ones dark, the plates of joints 13 lighter. Cervical shield not developed. Tubercles black, single, normal, dark, pointed.

StAGE V. Head rounded squarish, scarcely bilobed, the vertical notch obsolescent, flattish before, the sutures at apex of clypeus depressed; surface shagreened; yellowish, mottled and spotted with brown, heaviest on sides of lobes and in clypeal depression; width $2.3 \mathrm{~mm}$. Body normal, robust, tubercles roundedly produced, smooth, ii the largest, on joints 5 to 7 forming distinct cones, on $\mathrm{I} 2$ situated on a slight dorsal prominence, normal, iii to v closely surrounding the spiracle, two tubercles representing vi; no cervical shield, anal shields developed, triangular, but concolorous and not corneous. Skin minutely spinulose; spiracles large, black rimmed; setae distinct, dark. Varies from sordid gray to green without distinct lines or strong markings. There is a general indication of longitudinal lines, pale, marked with fine brown dottings. These lines are addorsal, subdorsal, suprastigmatal, and two subventral, but all are ill defined, especially the subventral ones. Feet pale.

Pupa. Cylindrical, normal, abdomen tapering, with three movable incisures; cremaster two stout spines joined at the base into a flattish plate; cases wrinkled; abdominal segments coarsely punctured. Length $\mathrm{I} 8$, width $5 \mathrm{~mm}$. 

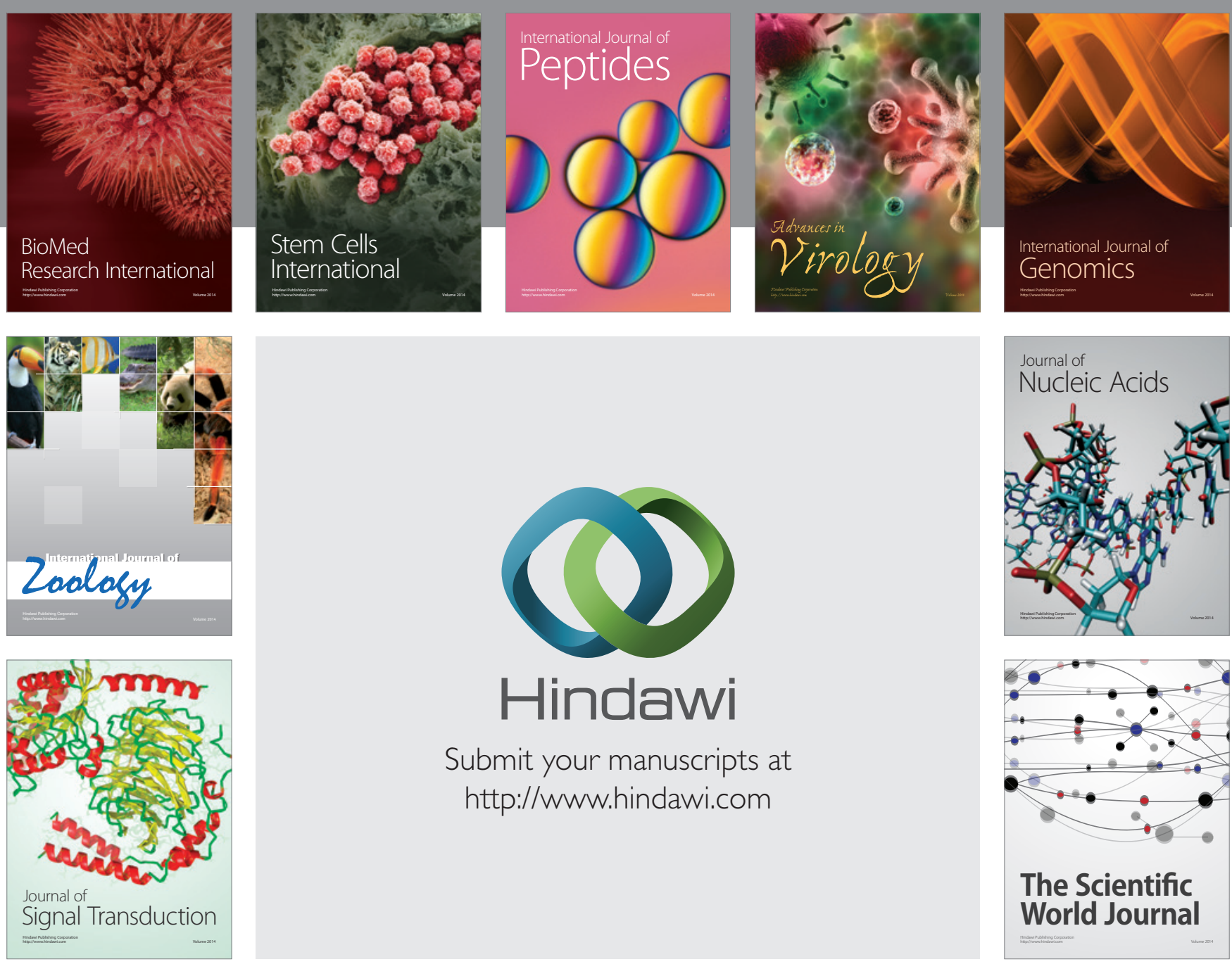

Submit your manuscripts at

http://www.hindawi.com
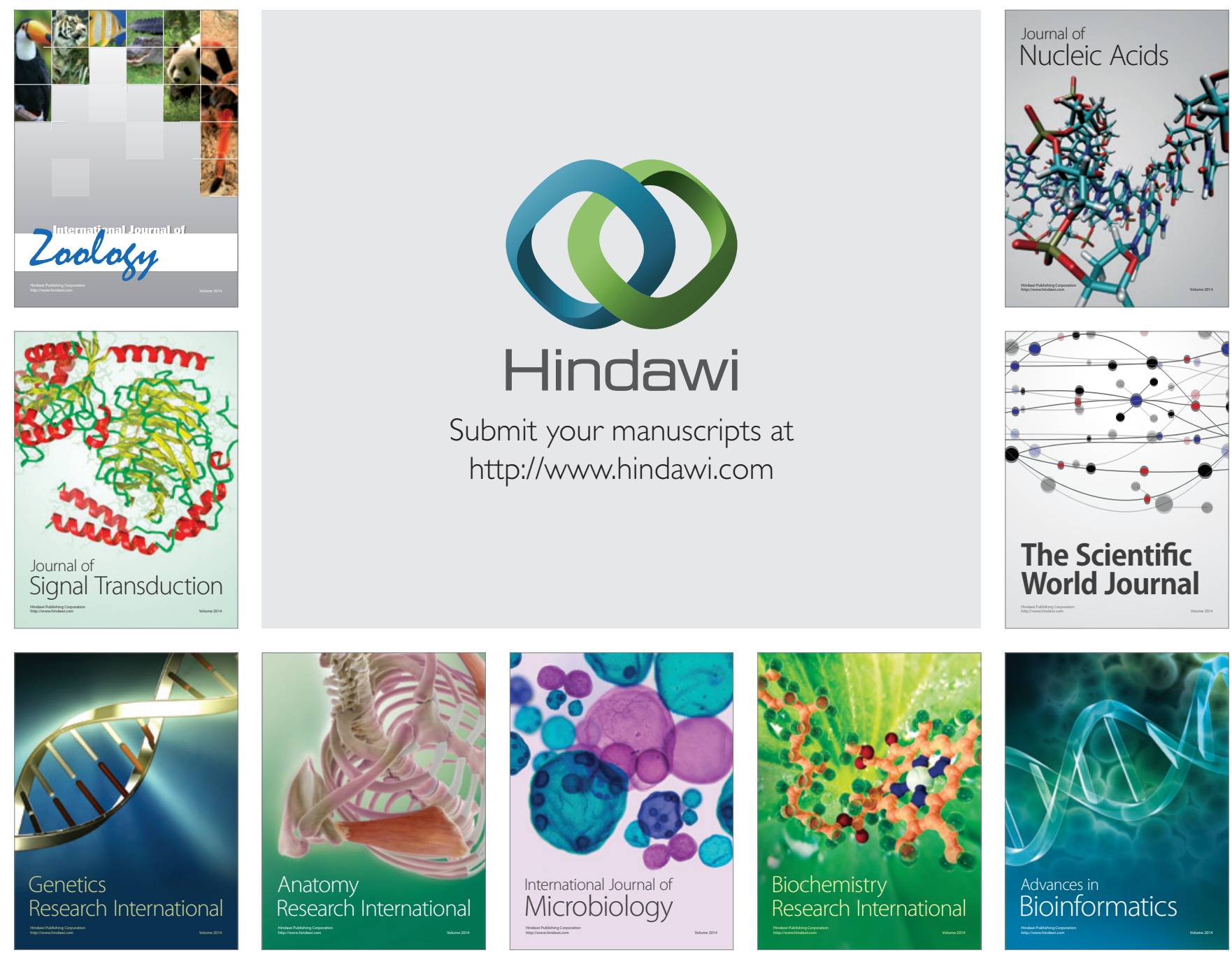

The Scientific World Journal
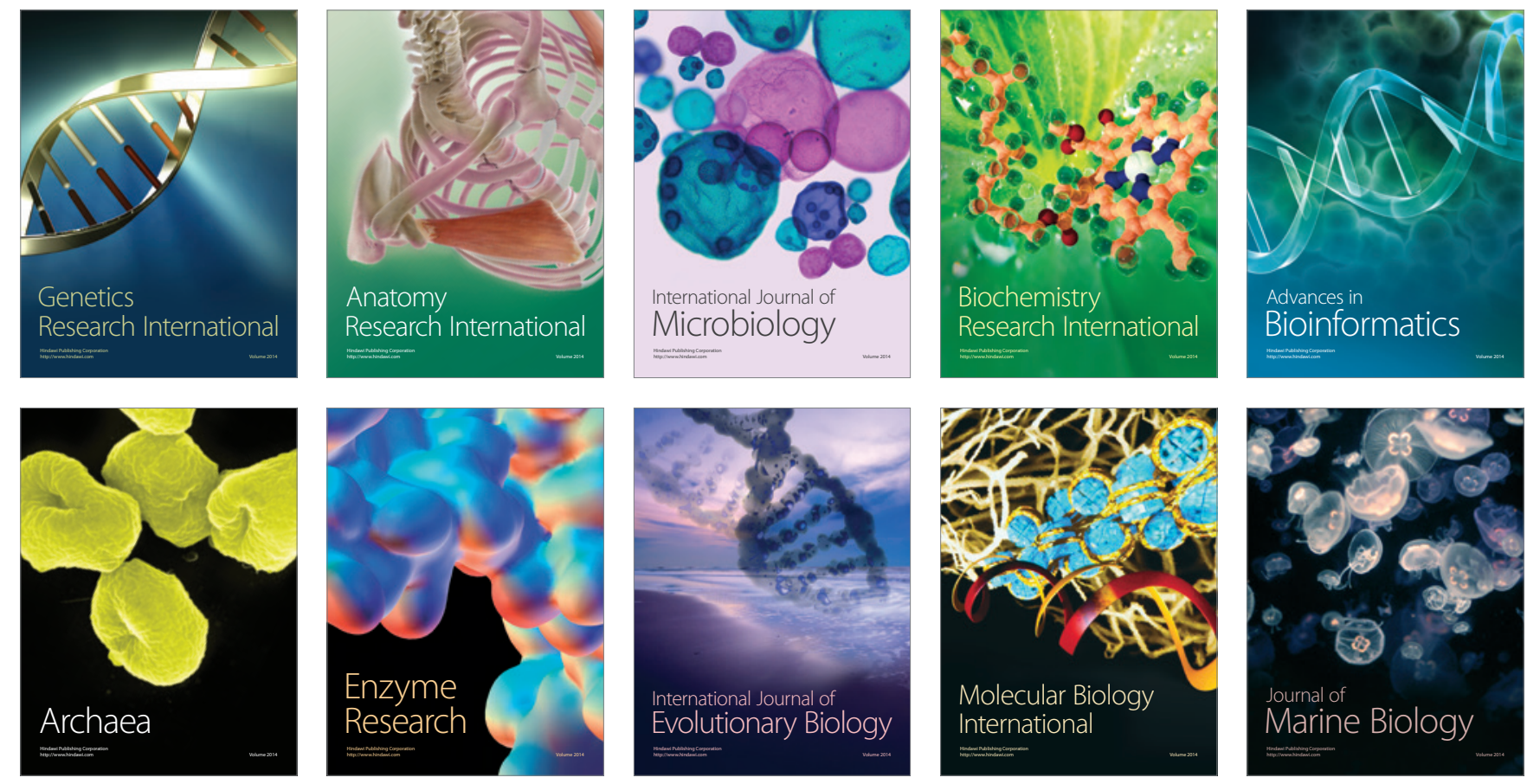